\title{
Pre-hospital data as risk predictors of seriousness among traumatically injured patients
}

\author{
Alexander Franzén, Kim L Schultz, Jens O Laursen, Christian B Mogensen* \\ From 6th Danish Emergency Medicine Conference \\ Odense, Denmark. 20-21 November 2014
}

\begin{abstract}
Background
Currently many hospitals activate a trauma team with a predefined large team of health care professionals as a response to a trauma call. For hospitals with limited resources, this is a demanding process, which weakens the overall hospital performance by allocating considerable resources to the trauma room. Most trauma calls are based on trauma schemes scores from a combination of physiologic- anatomic injury- and injury mechanism criteria. In the search for indicators which might be used for a more differentiated hospital response, the aim of this study was to investigate the relative importance of pre-hospital variables in identifying "high risk" patients.
\end{abstract}

\section{Methods}

The study was a historical prospective cohort study conducted at a level 2 trauma hospital in Southern Denmark. The inclusion criterion was traumatically injured patients above 14 years of age, requiring activation of the trauma team over a one-year period. The outcome was "high risk" patients, requiring one or more of the following: In-hospital stay more than 48 hours, orthopaedic or nonorthopaedic surgery performed, ICU stay, transfer to another hospital, or injury related death within 30 days. Logistic regression was used to evaluate the relationship between pre-hospital variables and high risk.

\section{Results}

Of the 393 injured patients included, 30.0\% were high risk patients. Statistically significant independent variables associated with high risk included anatomic injury criteria (OR $=5.5 ; 95 \%$ CI: 2.13-14.23), age 35-55 years $(\mathrm{OR}=2.7 ; 95 \% \mathrm{CI}: 1.31-5.55)$, age above 55 years $(\mathrm{OR}=$ 4.8; 95\% CI: 2.30-9.97), pre-hospital systolic blood pressure 90-110 $\mathrm{mmHg}(\mathrm{OR}=3.8$; 95\% CI 1.02-13.92),

\footnotetext{
* Correspondence: Christian.backer.mogensen@rsyd.dk

Emergency Department, Hospital of Southern Jutland, Aabenraa, Denmark
}

"pedestrian struck by motor vehicle" $(\mathrm{OR}=4.3$; $95 \% \mathrm{CI}$ : 1.42-12.76), and oxygen saturation $90-94 \%(\mathrm{OR}=3.4$; 95\% CI: 1.30-8.64).

\section{Conclusions}

Our findings demonstrate that age, systolic blood pressure, oxygen saturation, and anatomic injury criteria are associated with high risk traumas and should be considered for inclusion in a trauma team activation protocol and further tested in such a model. Besides pedestrians struck by motor vehicle, the mechanism of injury has revealed poor predictive capabilities.

Published: 16 July 2015

doi:10.1186/1757-7241-23-S1-A3

Cite this article as: Franzén et al.: Pre-hospital data as risk predictors of seriousness among traumatically injured patients. Scandinavian Journal of Trauma, Resuscitation and Emergency Medicine 2015 23(Suppl 1):A3.
Submit your next manuscript to BioMed Central and take full advantage of:

- Convenient online submission

- Thorough peer review

- No space constraints or color figure charges

- Immediate publication on acceptance

- Inclusion in PubMed, CAS, Scopus and Google Scholar

- Research which is freely available for redistribution
() Biomed Central 